\title{
Age and Aging in Computer Games
}

\author{
Hans-Joachim Backe \\ Ruhr-Universität Bochum \\ hans-joachim.backe@rub.de
}

One important property of canonized texts is their potential for interpretation. They are considered special and important because we conceive of them as being imbued with meaning that is not exhausted easily or quickly. With newer modes of expression, it is often difficult to recognize where this depth of meaning can be found. When defining the cultural value of computer games, one might be tempted to treat them like novels or movies and apply virtually unmodified aesthetic value systems to them. Instead of proving their status as an art form worthy of having a canon of its own, such approaches actually deny them any status at all, reducing them to bad copies of existing forms of communication.

To understand why computer games are an especially interesting cultural phenomenon and an art form, we need examples and discourses that highlight the medium's special properties. Chief among those is their incorporation of elements that are not strictly necessary for play and could be said to be non-ludic. Although a good computer game has to be, first and foremost, a good game, the existence and importance of factors that are not strictly necessary for play is undeniable. Visuals and sounds are necessary components of a game's user interface, but they always have additional denotations and connotations. While these elements remain purely decorative and irrelevant in some games, there are many examples where a strong interdependence or even a fusion with actual game elements can be observed. When many players interact in multiplayer games, group behavior and social dynamics are often as central to the overall design as game mechanics, while in anthropomorphic single-player 
games, narrative conventions inform the world design and simulation structure. In the past, research has often focused on establishing firm distinctions between play and narrative. To give an impression of the medium's unique qualities, I would like to do the opposite and show how the treatment of age in computer games blurs the lines between play and narrative. I will demonstrate the variety of possible treatments of age by discussing a number of role-playing games, action-adventures and strategy games, all of which expose a connection between play, narrative, and age.

\section{Concepts of Age and Aging}

Conceptualizing age is notoriously difficult, maybe because we cannot conceive a world without it. A person's age, measured in years, is one of the first data used to describe them. "However, aging cannot be simply conceptualized as 'attaining a higher chronological age"' (Baars 88). Empirically, it is made transient by the fact that there is no control group, because everybody ages (90). Statistically, it is hard to describe because it is intrinsic to life, yet totally unpredictable: Although growth, decay and death are omnipresent and irreversible biological processes, they can be continuous as well as spontaneous (91). Sociologically, there is the problem that the individual's personal experience of time cannot be standardized, although we are constantly subjected to institutionalized time schemes, especially on the grand scales of education and employment.

For these reasons, gerontology, the systematic study of aging, is (ironically) a young discipline, in which various radically different approaches exist side by side. One of the most recent textbooks on gerontology, the Handbook of Theories of Aging, distinguishes four fields of interest in connection with age: first, the causes and parameters of physical deterioration in connection with aging; second, the loss of cognitive function; third, society's responsibility towards elders; and 
fourth, the emotional burden of constant experiences of loss (Bengtson et al. 3-4). The four dimensions of age and aging describe the dimensions of gerontology as a discipline, but they are of little help in understanding the phenomenon itself.

Looking at the issue more abstractly, aging could be said to present itself as the discrepancy of chronological time and human development (Achenbaum 29-34), or, in other words, the independence of temporal and causal relations (Baars 89). The ways in which the human body and mind change while aging cannot be described sufficiently in terms of months and years. Jan Baars identifies three traditions of coming to terms with these problems (95-97). The first can be traced back to the fifth century B.C.E. and Augustine's appreciation of time as being realized exclusively through human perception. According to this approach, we experience existence as the present. Past events become more or less memorable not because of how much chronological time elapsed since they happened, but because of the specific and individual relevance we attribute to them. The second tradition is even older: Hesiod adapted Stoic thoughts on kairos, the right, opportune or supreme moment, in the seventh century B.C.E. This concept thinks of time as a sequence of opportunities, granted or denied by the gods. Many figures of speech have preserved the notion of 'the right time', of 'now or never', and we still have pretty fixed ideas of what behavior is acceptable in the different stages of life, so regardless of its theological backgrounds, this tradition has not lost its relevance today. The third tradition identified by Baars is narrative, which he (by way of Paul Ricoeur) calls the natural way of appropriating and expressing individual experience and a subjective evaluation of time. "Human aging is, inevitably, interpreted and connected with narratives about the value, glory, misery, happiness, and finitude of human life" (96-97).

As such, age has always held great fascination for the arts, especially for popular forms. "Popular art complemented scientific theory building in the Middle Ages. Artisans' depictions of the Journey of Life allegorized the 
human life, blending moral and religious casuistry with physical and biological causality" (Achenbaum 26). It is, therefore, hardly surprising that computer games have long started to incorporate age into their subject matters and game mechanics.

\section{Demographics}

Computer games aren't a medium that springs to mind when considering discourses of aging. Quite on the contrary, like fashion, they are frequently associated with eternal youth. As completely virtual, digital creations, their iconic avatars do not age. In the greater context of games per se, they are quite often associated with childhood. There is a notion that, at some point in time during adolescence, people lose their interest in games and focus on work and family. This has, of course, never been accurate. Grown-ups have taken part in playful activities since the dawn of civilization, and even today, there are certain games - the whole complex of gambling, for instance - that are perceived as inappropriate for children. ${ }^{1}$ Computer games have eroded these established notions. Demographics show that the average gamer is above thirty, well educated and reasonably well-off (Entertainment Software Association) meaning that there are a great many gamers well above forty and fifty. But not only player demographics have become diverse. ${ }^{2}$ Young professionals entering the gaming industry today will be in their early twenties, meaning that they already grew up with handheld games, 3Daccelerated graphics, and readily available online multiplayer matches. At the same time, some of the inventors and early innovators of the medium are still active in the industry: Shigeru Miyamoto, Richard Garriott, Peter Molyneux, and Sid Meier, to name just a few. It may seem a little farfetched, but the equivalent in the world of literature would be that Homer,

\footnotetext{
${ }^{1}$ Roger Caillois devotes an extensive chapter to the significance of stakes in games (145-161).

${ }^{2}$ Nonetheless, age group exhibit different play behavior (cf. Nap and de Kort).
} 
Shakespeare, and Joyce were still around, publishing new texts, collaborating with twenty-first century authors.

Thus, the depiction of aging in computer games could be conceived of as being an almost inevitable side-effect of aging players and developers through processes of identification. But even though demographics are important, they are far from the only reason for the presence of age-discourses in computer games. If it was all a matter of identification with the avatar, only gorgeous young women would want to be playing Lara Croft. With an attractive female avatar, it is easy to see that projection, role modeling and voyeurism are equally important factors for different player groups, which could all be said to be based on demographics. But how does one account for ugly, balding, middle aged men attracting significant numbers of players?

\section{Cosmetics of Age}

Role-play would be one rather obvious explanation that encompasses the before-mentioned factors. Role-playing games sometimes feature age as one of the tools for enabling the player's complete control over the avatar's character and appearance. Bethesda Softworks's The Elder Scrolls: Oblivion (2006) allows the creation of a character of any age, even for members of non-human races such as Elves. Yet, the avatar's age is a completely cosmetic decision without any impact whatsoever on the character's personality or abilities. This is even apparent in the interface, which places age in its 'appearance' menu, right next to skin tone and hair color. In the character sheet that displays all attributes with gameplay relevance - strength or agility, for example -, age does not even appear afterwards. It is, for all purposes apart from emphatic roleplaying, quite irrelevant.

As such, we might expect role-playing games to use this strategy for incorporating age rather frequently - but they do not. Some games, such as Fallout (Interplay, 1997), used age as a characteristic at a time when 
the avatar's appearance had to remain generic for technical reasons. Although the relevance of age, just like that of gender, is minimal in Fallout, it influences the way the game is played. At a number of instances, non-player characters will comment on the avatar's gender or age and react in a slightly different way. ${ }^{3}$ Fallout 3 (Bethesda Softworks, 2008) also uses age in an ingenious way by integrating the creation of the avatar with the exposition of setting and characters. Instead of simply choosing attributes from a menu, Fallout 3 has the player witness a very condensed youth of the avatar, letting him or her choose at key moments (like birthdays or an evaluation at the end of education) certain facets of the avatars personality. Here, all three concepts of time and aging identified by Baars work together.

Surprisingly, few other role-playing games have attempted to integrate age and aging, and many have eliminated age completely, especially if they are very much focused on creating an atmosphere and facilitating identification with the avatar. Vampire: The Masquerade Bloodlines (Troika/Activision, 2004) may at first seem like a bad example, because it deals - as the title makes quite clear - with Vampires. Yet this breed of fictional undead has been associated with age at least since Anne Rice Interview with the Vampire, published in the 1970s, where the child vampire Claudia plays a significant role. Add to that Oblivions geriatric elves, and the omission of age becomes quite noticeable. Bloodlines allows the choice between various clans of Vampires and differentiates its game experience considerably between male and female avatars. As soon as the game starts, the reasons for the omission of aging becomes apparent. Bloodlines has a pronounced storytelling bias, meaning that the game is geared toward offering involvement in a coherent narrative rather than the greatest freedom of choice. The expository movie sequence shows how the avatar becomes a vampire after being bitten at the end of a onenight-stand - a situation we would associate most strongly with people

3 Several sources comment on these features, which seem to be also present in Fallout 2 (Interplay, 2001). Cf. Marts and Namjoshi. 
between, say, eighteen and thirty. The youth and relative innocence of the avatar is a determining design factor for both the game mechanics legitimizing the building of a character from scratch - as well as the story, where he or she becomes trapped in a power struggle between the different clans and individuals. This way, the treatment of age in Bloodlines fits with the game's general tendency of limiting the player's freedom in order to guarantee a greater degree of narrative coherence.

The same can be said about Fable: The Lost Chapters (Lionhead/Electronic Arts, 2006), another role-playing game from the same time-frame, although it differs enormously from Bloodlines in that it directly implements aging in its game design. Fable allows for no initial choice of character whatsoever: At the outset, the avatar is a boy who has lost his family to an attack of robbers and gets adopted by a wizard called Maze. The narrative structure that strings together individual quests is even tighter than that of other role-playing games, allowing for little sidetracking. To this end, the game's first quest is the rite of passage the boy has to go through to become accepted into the 'guild of heroes,' after which he changes from a boy to a young man After this initial maturation, the avatar grows older as he gains experience, so that not only his equipment and abilities, but also his physical appearance mirrors the changes he goes through. These changes are, once more, not at all related to human aging. They are symbolic, pointing out the epic dimensions of the game's main quest. Where Bloodlines evades age to make its story more coherent, Fable aims solely at making the avatars development more tangible. This is even more apparent in Fable's treatment of the avatar's morals, which are signified by his developing a halo or horns, depending on whether he is good or evil. Other aspects, such as narrative verisimilitude, are widely neglected: While the avatar can age by over fifty years, the game's other characters do not age at all - which is all the more irritating as the story involves several meetings with his sister and his mother. Thus Fable combines the cosmetic aspect of Oblivion with the narrative focus of Bloodlines to achieve a very 
subjective - and in an emotional way quite truthful - realization of aging. The changing appearance of the avatar reminds the player of the adventures and the development the character has gone through, even though the world around him has not aged. As such, Fable's take on aging stands in the tradition of Augustine subjective perception of time.

\section{Character-centered Action-Adventures}

In action-adventures, the narrative structure is often even more pronounced, as the player's agency - Janet Murray's term for the influence upon the game-world (Murray 153) - is reduced in favor of coherence and motivation. This facilitates a kind of immersion that is more akin to traditional, linear narrative than to that found in role-playing games, where a certain degree of freedom allows the player to immerse him- or herself in the simulated world and its inhabitants outside the grand scheme of an overarching plot. The games I will talk about now have a strong focus on narrative, and as such, they use age mostly as a storytelling device, for example by deriving the main character's motivation from his or her age and background. Yet these storytelling choices also influence the game's design and content. This is, for example, apparent in the subgenre of sneaking games, in which thieves or secret agents have to achieve their goals unnoticed by the world around them. In virtually all of these games, the avatar is a male, cynical, fortyish veteran who has been recalled from retirement (as in Metal Gear Solid and Splinter Cell) or is constantly thinking about retiring (as in Thief). This type of character makes not only for interesting storytelling, he is also a prerequisite for this kind of gameplay. To be believable, the avatar has to be a patient, seasoned man who already has the experience and wisdom of age while retaining the agility and power of a younger man. Drawing on Michael Riffaterre's concept of verisimilitude as comparing stories with 
mental scripts that are often derived from fiction, ${ }^{4}$ I would argue that this is not so much a stereotype as an archetype, a kind of hero-figure that can be traced from Ulysses to James Bond and beyond - the man for whom the right moment has come.

Even though game demographics are, as mentioned above, quite diverse, adolescents are maybe the most important age group on the computer gaming market. As such, it can be hardly surprising that effects and impressions of puberty sometimes form the basis for games. One very telling example, American McGee's Alice, is more of a sequel than an adaptation of Lewis Carrolls' Alice-Novels. It extrapolates the established fictional characters and puts them into new surroundings, but the changes are not physical. Alice has lost her family in a fire for which she subconsciously blames herself. Confined to a mental institution, she revisits wonderland, only to find it much more violent and dangerous than previously. While it is easy to attribute this change to the game design, which focuses on a mix of fighting and jumping puzzles, or even to the use of a graphics engine originally programmed for first-person shooters (van Looy), it appears that the protagonist's age is also a key factor. This Alice is no longer the little girl of Carrolls' writing, Tenniel's illustrations or the Disney movie. She has entered puberty. Her rapidly grown, scrawny body and her earnest, disillusioned face form a stark contrast to her being still dressed like a child, in short skirt and frock. That the wonderland she has to travel to regain her sanity lacks all innocence and peace is a very fitting simile for the troubled mind of a fourteen-year-old. Her struggles to survive in the hostile environment of a wonderland that doubtlessly exists in her mind only are a psychological rite of passage, in which she learns to be treated like a grown-up and think of herself the same way, thus

\footnotetext{
${ }^{4}$ Riffaterre has argued that, in order for a story to be processed as truthful by the reader, it has to confirm to rules of verisimilitude, especially when it comes to character motivation. Recipients expect from a narrative "[...] a compellingly visible coherence in the sequence of causes and effects." According to Riffaterre, verisimilitude is not judged by a comparison with reality, but with personal and collective experience forming frames of reference. "These mental frames of reference, however, are not just habits of thought; they constitute potential ministories, ready to unfold when needed and ready for reference when alluded to" (Riffaterre 4 ).
} 
coming to terms with her childhood trauma. In connection with Baars' age-concepts, this psychological process could be conceived of as an instance of pre-conscious narrative.

A more drawn-out coming of age is found in Ubisoft's Prince of Persia: Sands of Time trilogy (2003-2005), which has its hero mature as the game series progresses. In the first part, the nameless prince is a buffoonish, reckless youngster, the Persian king's spoiled son, to whom ransacking enemy cities is nothing but great fun. When the evil vizier of a neighboring country tricks the prince into releasing the deadly magic Sands of Time, the prince has to face a catastrophe of his own making, and for the first time in his life, he has to take responsibility for his deeds. Everybody around him is transformed into monsters, even his father, whom he has to kill in self-defense. Although the prince can undo his deed, he has become cursed, both literally and figuratively. In the sequel, a demon has been sent to punish him for tampering with the Sands of Time, but the prince is equally haunted by the demons of his psyche. The memory of killing those that he loved is troubling him, all the more as it has become associated with his falling in love for the first time with Farah, a princess from one of the defeated enemy countries. When the prince uses the Sands to turn back time and restore the life of his father, he also makes Farah forget her love for him. Thus he has to live with the impression of a double loss, one of an unwanted past, one of a cherished future. What is more, he cannot win Farah's love back - he is, after all, the son of the enemy ruler, and without the possibility of proving himself a hero, the prince's arrogance outweighs his charms.

In part two, The Warrior Within, the prince sets out to cleanse himself of the curse. In due course, he has to face the actual outward demon haunting him, but this fight is mirrored by his inner turmoil and his sexual frustration. The prince's two main opponents are two women, Shahdee and Kaileena. Both are depicted in an extremely sexualized way, but while Shahdee is aggressive and dominant, Kaileena appears as passive and demure. Before the end, the prince has to fight both women, 
and while Shahdee has to be vanquished, it is possible to arrange a truce with Kaileena. The game has two endings, one in which the prince frees himself of the curse by offering Kaileena to the demon, the other in which both work together to defeat the demon. Part three, The Two Thrones, picks up on this ending and has Kaileena and the prince return to his home in Babylon, only to find the city under siege by the evil vizier from part one. Kaileena is killed, and the prince gets one final chance at redeeming himself by stopping the vizier from using the Sands of Time. This task reunites him with Farah, who is no longer the damsel in distress from part one, but a grim and resolute warrior princess. In the end, he has destroyed the Sands of Time for good and won the love and respect of Farah as the mature, experienced man he has become not only through his adventures, but also through confronting his fear, his ignorance and his sexual urges, all of which are represented as metonymic characters of the story.

This narrative treatment of maturation is not only mirrored in changes of the character's appearance - which sometimes, like in the introductory movie of the second part, is even accentuated by lighting that makes him seem prematurely graying -, but also by the game mechanics. Part one has relatively easy controls, gives many hints for the solution of its puzzles, and its violence is very stylized and cartoonish. Part two breaks with all these conventions. The puzzles now require much trial and error. Fighting becomes more diverse, but also decidedly more difficult and gory, with fountains of blood and chopped-off heads in the first few minutes of play. To make the breaking of conventions even more apparent, the first boss-fight does not happen at the end, but already at the beginning of the first level, and it is set up in a way that makes it impossible to win. Part three introduces new, optional ways of interacting with the environment and enemies, but it also makes things even more difficult for the player by having the prince manifest symptoms of schizophrenia, which repeatedly reverse the game's basic principles. The maturation of the prince is thus mirrored by evolving the childish 
simplicity of the first part to a violent, sexualized, adolescent second and a diverse and complex third part. The subjectivity of memory and its narrative dimension are thematized by the use of a voice-over narration throughout the series that is clearly situated after the fact.

There are also games that are constructed around older characters, even outside the aforementioned sneaking genre. Kane and Lynch: Dead Men (IO Interactive/Eidos, 2007) deviates from most standards by choosing ugly, middle-aged men as avatars and relying on their potential as intriguing characters. Their story is dominated by psychological pressure upon and the dynamics between the protagonists. Their choices and behavior are determined by their previous lives, does not give the player much influence on the game's progression. Only right before the end, the player gets to make one choice for the avatar, but it is a crucial one: to save his daughter's life or help the friends who saved her for him. More importantly, the moment and the context of shifting the decisionmaking to the player highlight the central role of age in the story. At the end, the characters have caught up with their past. After coping with previous mistakes, the present now becomes really important because a new life-stage begins. The design choice of foregrounding a mature character sets the stage for further meaningful, human choices: There is no need for an overblown "save the world"-scenario to motivate the player. Instead, we are presented with an engaging moral dilemma: How does a criminal win back the trust of his daughter, when what she despises most about him is violence, but violence is the only way of saving her life. Despite its sometimes extreme displays of violence, Kane \& Lynch: Dead Men tells a morally rather complex story about discovering that the wrong choices made throughout a lifetime cannot be righted by a single act of greatness. The game leaves the player a choice in the end, but it is an unfair one, deciding between friends and family, all of which Kane owes a lot to. To make things worse, there is no happy ending to the game: no matter how the player decides and acts, the game ends with everyone but Kane dead or dying. When the final movie sequence shows 
the protagonists on a small boat, adrift along the South American coast, moving into shadows and fog, Kane's realization of the inevitability of accountability and death is transformed into pictures. Here, the archetypical hero for whom the opportune moment has come is turn on its head, resulting in a depiction of age as a time where the right time for actions and decisions has been passed by.

\section{Strategy Games and Implicit Narrative}

My final example is from a genre not usually discussed in connection with narrative. Crusader Kings: Deus Vult (Paradox Interactive, 2007) is an impressive example of how age can be used as a game device without any explicit attempts at storytelling. Crusader Kings allows the player to control a European dynasty throughout the middle ages, but unlike most other games of this genre, it does not focus mainly on methods of conquest, as does The Creative Assembly's well known Total War series or the classic board game Risk. Although warfare is a part of Crusader Kings' game principle, it is less important than the subtler forms of strategy like befriending ones vassals, balancing the needs of clergy, nobles and commoners, and enforcing laws and customs that guarantee prosperity and stability. What also sets the game apart from its peers is that it basically is a simulation of human behavior. Every lord and courtier at all the courts of the game world has desires and wishes, which are controlled by complex scripts linking the character's personality to the political, social and personal situation. There are only four statistics governing the effectiveness of characters in terms of gameplay, but a host of traits that define their personality. The system is, obviously, still reductionist, but the interaction of the thousands of people of rank within the simulation results in very unpredictable results.

Age is a major factor in the game. Every child is born as a clean slate, that is, he or she has values of zero in their statistics. But the game features a hereditary system that has the parent's characteristics and 
even appearance influence that of their children. Together with a chosen path of education in the military, at court, with a noble or in a monastery, the hereditary traits determine how a personality develops. When children reach adulthood, they become a full personality, which manifests in a number of changes. Children have no portraits in the game interface, they cannot marry and acquire only a few personal traits through their decisions. Once they are grownups, they will strive to distinguish themselves by asking to be made a chancellor to the king, or, if they are of royal blood, to be given a county or duchy. They will continue to quarrel with siblings and other people from court - which is the only way except for illnesses to pick up traits even as a child -, they will form new friendships and rivalries through social intercourse, they will have lovers, maybe even children. Most grave decisions in their lives are made by the player, but there are no easy choices. This is mostly because the game not only considers how a person really is, but also how they are perceived by others and how a certain characteristic might be valued differently by the various political forces. An act of charity may be regarded as pious by the church while making the character seem week to his vassals. As a character grows old, he or she will accumulate a number of traits which will result in very interesting and complex personalities.

Let me give you one example of how age affects gameplay in Crusader Kings. In one campaign as the Kingdom of Denmark, I decided to have my king relinquish a number of his dominions to his oldest son upon reaching adulthood. The player has not as much influence over a vassal's court as he has over that of the supreme ruler, so I could only watch as the prince became a ruler himself. What was meant as a means to have the prince gain some wealth and respect became a rather permanent solution as the king proved to be exceptionally long-lived. With time, I neglected the crown-prince's duchy, and when he eventually became king, his son had already reached adulthood and taken a wife. Arranged marriages are one of the game's key factors in influencing the future well-being of the dynasty, and the player can improve the odds of a 
successful marriage by choosing a spouse from a not-too-alien culture with similar or compatible characteristics. Two forgiving and modest persons will cope with each other, while marrying a chaste and honest woman to a lustful, deceitful man almost always ends in disaster - which is exactly how the marriage of the new crown-prince turned out. When he followed his father to the throne, his wife had become "disloyalty incarnate," as the game describes a loyalty-value of zero. She did not bear him any more children, because she had taken a young lover from court, which in itself subverted the ruler's authority. Because of their youth and the conflicting traits, the simulation had their relationship deteriorate even more. After she had started to appear publicly with her lover several times, the queen began to spread rumors about the king, which started to turn his court against him, and quickly, both the steward and the marshal started opposing the king - which means that the army will be ineffective and the state may become bankrupt.

Crusader Kings doesn't offer the opportunity to banish or divorce a family member. I could have given the queen a county of her own and gifts to try and improve her loyalty to a workable level, or, if that failed, provoked a war with her county to be able to treat her as an enemy. Instead, I tried to assassinate her - a decision I quickly regretted. The assassination was a success, but became public, and within months of game time, the kingdom that had taken over two hundred years of game time to build lay in ruins. Vassals defected to the next most powerful king and some even declared war. Courtiers left in droves, until I could only appoint foreign diplomats as ministers of the crown - only to see them accused of heresy and executed by the inquisition. Thus, the marriage of a foolish young prince was the most decisive moment in a hundred years of simulated history. 


\section{Conclusion}

The example of Crusader Kings brings us back to the initial gerontological assumption that human aging cannot be conceptualized without resorting to narrative. By incorporating age in their content and rules, computer games invite a narrative reaction towards them. Depictions and simulations of age and aging can be achieved in a compelling, meaningful manner that not only contextualizes and defines characters. As universal human experiences, age and aging are able to incite emotional responses in players that create motivation and immersion. Similar to the more frequently used experiences of fear and vertigo or traits like curiosity and ambition, age and aging can bridge the gap of narrative and game. While the simulation of these factors mirrors the way we experience them, their narrative treatment resembles our remembering them and coping with them.

Even though a number of genres had to be completely omitted from my argument - most notably life simulations like the immensely popular The Sims (Electronic Arts, 2000) -, I believe to have proven that age and aging can be used in games to blend play and narrative in an organic manner that gives them depth beyond what is achieved in most other ways.

\section{References}

ACHEnBAuM, W. Andrew. "A Metahistorical Perspective on Theories of Aging." Handbook of theories of aging. 2. ed. Ed. Vern L Bengtson. New York: Springer, 2009. 25-38. Print.

BAARS, Jan. "Problematic Foundations: Theorizing Time, Age, and Aging." Handbook of theories of aging. 2. ed. Ed. Vern L Bengtson. New York: Springer, 2009. 87-99. Print. 
BENGTSON, Vern L, et al. "Theories About Age and Aging." Handbook of theories of aging. 2. ed. Ed. Vern L Bengtson. New York: Springer, 2009. 3-23. Print.

CAILLOIS, Roger, and Meyer Barash. Man, play, and games. 1. Illinois paperback. Urbana, Ill.: Univ. of Illinois Press, 2001. Print.

ENTERTAINMENT SOFTWARE ASSOCIATION. Industry Facts, 2010. Web. 18 Jun. 2010. <http://www.theesa.com/facts/index.asp>.

MARTS, Nicholas. Fallout Best Ending FAQ/Walkthrough. Web. 18 Jun. 2010. <http://www.gamefaqs.com/pc/197289fallout/faqs/41841>.

MURRAY, Janet Horowitz. Hamlet on the holodeck: The future of narrative in cyberspace. Reprint. Cambridge, Mass.: MIT Press, 1998. Print.

NAMJOSHI, Omkar. Fallout 2 Game Guide. Web. 18 Jun. 2010. <http://www.gamefaqs.com/pc/63576-fallout-2/faqs/16657>.

NAP, Henk Herman: Ijsselsteijn Wijnand A., and Yvonne A. W. de Kort. Age Differences in Associations with Digital Gaming. Breaking New Ground: Innovation in Games, Play, Practice and Theory. Proceedings of DiGRA 2009. Web. 18 Jun. 2010. <http://www.digra.org/dl/db/09287.31341.pdf>.

RIFFATERRE, Michael. Fictional truth. Baltimore: Johns Hopkins Univ. Pr., 1990. Print. Parallax.

VAN LOOY, Jan. Player Identification in American McGee's Alice: a Comparative Perspective. Web. 18 Jun. 2010. <http://underthemask.wikidot.com/janvanlooy>.

\section{Games Cited}

Crusader Kings: Deus Vult (Paradox Interactive, 2007)

Fable: The Lost Chapters (Lionhead/Electronic Arts, 2006)

Fallout (Interplay, 1997)

Fallout 3 (Bethesda Softworks, 2008)

Kane and Lynch: Dead Men (IO Interactive/Eidos, 2007) 
Metal Gear Solid (Konami 1998)

Prince of Persia: The Sands of Time (Ubisoft 2003)

Prince of Persia: The Two Thrones (Ubisoft 2005)

Prince of Persia: Warrior Within (Ubisoft 2004)

The Elder Scrolls: Oblivion (Bethesda Softworks, 2006)

The Sims (Electronic Arts, 2000)

Thief (Looking Glass Studios/Eidos, 1998)

Tom Clancy's Splinter Cell (Ubisoft 2002)

Vampire: The Masquerade - Bloodlines (Troika/Activision, 2004) 